\title{
Research on the cooperation mechanism between higher vocational education and enterprise
}

\author{
Luo Xiao Hui \\ Chongqing College of Electronic Engineering Chongqing 401331 \\ Email: luohui54@yahoo.com.cn
}

\begin{abstract}
The significance of the implementation of the existing mode of school enterprise cooperation, and insufficient analysis, pointed out the challenges in school enterprise cooperation problems, and then puts forward the solving method of school enterprise cooperation problems: through the establishment of effective legal protection, establishing the evaluation mechanism, incentive mechanism and development mechanism to realize the cooperation of higher vocational education.
\end{abstract}

Keywords: school enterprise cooperation; legal protection; evaluation mechanism; incentive mechanism

\section{Introduction}

With the development and deepening of occupation education, the higher occupation colleges received great attention of the party and the government and has achieved great development, in order to improve the cultural quality of the whole nation, occupation skill quality, so as to improve the degree of skilled labor and labor skills, for the national economic construction service [1]. How to realize it, in which the school enterprise cooperation mode has already got the high degree of the whole society, and has been put into practice step by step. School enterprise cooperation, and will produce a combination of teaching, is a good path to success of the occupation education, it can realize the complementary advantages of school and enterprise resource sharing, so as to get rid of the traditional teaching pattern for occupation colleges, higher occupation colleges and enterprises to jointly improve the practical talents in cultivating talents.

\section{2 problems in the current higher vocational education}

In the current higher vocational education in the face of problems, mainly in the following two aspects.

\section{1 legal and institutional issues}

In foreign countries, such as Singapore, Germany, the United States and other school enterprise cooperation can achieve success, are in the country developed a more perfect laws and regulations, and strictly implement the. Such as the German government has developed the "labor Promotion Law", "Vocational Education Law" to regulate the school enterprise cooperation in the three party relations: including enterprises, schools, students in the rights and obligations are made clear. But the law of our country, rarely involved in school enterprise cooperation provisions, which makes the school and enterprise cooperation on mode, management mode, operation mode and development direction, in a "anarchy". National orientation in school enterprise cooperation and the role is not clear, lack of organization and management in the organization and coordination, resulting in the cooperation of schools and enterprises "fight the enemy separately, the cooperation between the lack of organization and coordination, is used in a state of disorder, the government basically not involved in school enterprise cooperation to carry out effective management is not more. No guidance work. At the same time, because of the lack of government involvement, cooperation exists blindness, enterprises on the development of the industry for deep understanding of program is far greater than the school, the training can not keep up with the pace of development of the industry and society development goals in talents in higher vocational 
colleges, it will seriously affect the actual effect of school enterprise cooperation.

In addition, different teaching in Higher Vocational Colleges and enterprises between the goal, the ultimate goal of the enterprise is to enable enterprises to get more profits, and higher vocational colleges is to pay more attention to the cultivation of talents, the change in teaching training plan and implementation of a certain degree of difficulty, and there is a certain lag, so the enterprise cooperation is not consistent in the case of the target, the cooperation between the two sides of the power is insufficient, the government really needs to participate in the form of fixed and constraints of law and system, for enterprise cooperation, supervision and coordination, and formulate relevant incentive measures so that both sides can realize the true meaning of the Enterprise Co [2].

\section{2 lack of incentive mechanism and evaluation mechanism}

Mentioned that due to the inconsistency between the school and the enterprise, many enterprises think and school cooperation, in the short term there is no interest at all; and higher vocational colleges as a result of the society pressure to carry out teaching reform, through school enterprise cooperation, and that improvements in the teaching plan and the implementation of more trouble, and really want to participating in the cooperation of enterprises enthusiasm is not high so that the cooperation is very difficult. In this context, it is necessary for education department, human resources and social security departments and other government agencies to formulate the corresponding incentive mechanism, to actively participate in the cooperation between enterprises and schools, from the tax incentives, financial [3].

However, due to the cooperation between school and enterprise is still in the growth stage, the supervision and evaluation mechanism of the cooperation between schools and enterprises has not been established. Since the state did not establish special organization for cooperation and coordination cooperation, there is no relevant appraisal standards, rewards and punishment standards; at the same time, the industry has not formed on the enterprise internal supervision and evaluation mechanism, the third party organization of independent enterprise are very few, so far, a bit more famous is a Chinese survey named "Max", in the school graduates six months after graduation, conducted a questionnaire survey, but there is also considerable water, some schools in order to improve the results of the investigation, the teacher pulled the relationship with the students, or adopt other measures to improve the effect of the [4] questionnaire.

\section{3 implementation of school enterprise cooperation}

As mentioned above, in the current our country school enterprise cooperation also mainly exists these two problems, for this problem, to realize the true sense of the school enterprise cooperation, we need to solve these problems.

\section{1 legal protection}

The legal guarantee for the cooperation between enterprises and enterprises is the first problem to be solved. Of course, the legal problems come from the practice, the law is not perfect, not perfect. The solution is: one is the experience from foreign countries such as the United States, Germany, Japan, Singapore, Britain and other countries, have relevant experience of school enterprise cooperation, of course, in reference to China's education, with reference to the current situation of enterprise and social process, cannot completely copy. Two is a wide range of Vocational Colleges and universities in the country to participate in school enterprise cooperation (of course, can also include other enterprises) for comments, on the basis of summary. Only by formulating the laws and regulations, can the school, enterprise, students in the school enterprise 
cooperation in the rights, responsibilities and obligations are clear. After the legal system, in the implementation process, it is necessary to strengthen the cooperation between law enforcement and supervision, the real guarantee of the smooth implementation of the school enterprise cooperation [5]. According to the law enforcement supervision, the dominant party of government, and the party should include education departments, industry associations, Department of human resources and social security, finance and other departments, on the cooperation of enterprises and enterprise occupation education occupation colleges in cooperative planning, resource allocation, financial security, supervision and evaluation supervision bureau. Since the information network is very developed, the results of the supervision, in the form of official website to the community to be publicized, which will greatly promote the school and enterprise cooperation in school and enterprise to achieve greater and better results.

\section{2 establish evaluation mechanism and incentive mechanism}

It is necessary to establish the evaluation mechanism of school enterprise cooperation, the actual effect of this relationship to cooperation, the need for government organization, higher vocational colleges in the country, hold regular seminars and between successful and desirable experience, at the same time, can also be used as a research topic on the national level and given three to five years of research and practice, the expert review, the research results well, the real implementation, the implementation of a good reward, and to all the results of comprehensive summary, take long repair short, then the promotion of [6]. In the incentive mechanism, to participate in school enterprise cooperation, according to the specific level of participation and assessment of the effectiveness of the class, the implementation of incentives in recognition. The school, in the recruitment of students in Higher Vocational Colleges under enormous pressure, can expand the social influence, improve the visibility of the school, after continued enrollment must be good; and to the enterprise, tax, and enterprises in the promotion, will play a more obvious good social effect. From the long-term social development, through school cooperation, students master the business needs of the knowledge and skills, both to improve the productivity of enterprises, and to improve the teaching effect of the school, is a win-win situation.

\section{3 establish school enterprise cooperative development mechanism}

The current society has changed from pure focus on education, the ability of light to show to present both the ability and degree, and further more to the ability for the trend is gradually forming value concept of "society advocating skills". Industry, business and schools are moving toward integration, in the task of achieving highly skilled personnel training, school enterprise cooperation mechanism is only more standardized and carried out, in order to further reflect the significance of higher vocational education [7].

The development of an enterprise needs high skill talents, the school only cultivate talents to meet the needs of enterprises, more reflect the school's educational significance, both needs and goals is the same, through the establishment of school enterprise cooperation, enterprise establish productive practice base in productive practice base in Higher Vocational Colleges and enterprises as the main body, the basic theory of teaching by higher vocational colleges, and master the practical skills training and the enterprise to achieve. The establishment of productive practice base can be formed by the government's participation, the establishment of schools and enterprises together, clear government, schools and enterprises of the rights and responsibilities of the parties to the distribution, income distribution, property management, etc.. Through the cooperation between schools and enterprises, schools and enterprises can realize the realization of resource 
sharing in information, culture, human resources, and can solve the cultivation of talents in Higher Vocational Colleges and enterprises between the use and management of talent contradiction, can make higher vocational education practical, forward-looking and open concept, also can make enterprises it is difficult to solve directly can bring real benefits to the recruiting talents for enterprises of the problem [8]. Therefore, through the establishment of school enterprise cooperative development mechanism for Higher Vocational Colleges and enterprises is bound to be a win-win result.

\section{Summary}

To strengthen the cooperation between Vocational Colleges and enterprises, it is common for high skill talents adapt to create the only way which must be passed under the new situation, this paper makes an analysis on the face of the cooperation situation in China, and puts forward some corresponding methods to solve the problems, the higher vocational colleges and enterprises to improve practical talents.

\section{Reference}

1 Liu Yanlong. Research on the mechanism of college enterprise cooperation on the connotation construction of Higher Vocational Colleges[J]. China Education Journal. 2014 (5):63-65

2 Shi Weiping, Lan Xiaoyun. Construction of enterprise cooperation mechanism in Higher Vocational Colleges under the time varying system [J]. Research on the development of education. 2013(13):15-19

$3 \mathrm{Xu}$ Zheng. On the integration of college and enterprise culture in Higher Vocational Colleges [J]. Journal of Hebei University of Economics and Business. 2014(6):111-113

4 Huang Huang. A comparative study on the mode of school enterprise cooperation in Higher Vocational Education [J]. 2004, 25 (28): 15-18

5 Wang Xin, Dong Mingming. Based on employment oriented vocational college enterprise cooperation [J]. China Vocational and technical education.2014 twenty-eighth, 89-91.

6 white crystals. Actively promote the school enterprise cooperation and work study combination of vocational education mode [J]. career.2013 (6): 28

7 management flat. The establishment of the national leading mode of Vocational Education -- A Study on the recognition of the school enterprise cooperation and work study combination [J]. China high education research. 2013 (6): 88-91.

8 Wei Shuo, Hui Jing Hui. Research and Practice on the talent training mode of school enterprise cooperation in rural vocational education [J] Journal of Suzhou Institute of education.2015,18 (1):

47-49. 